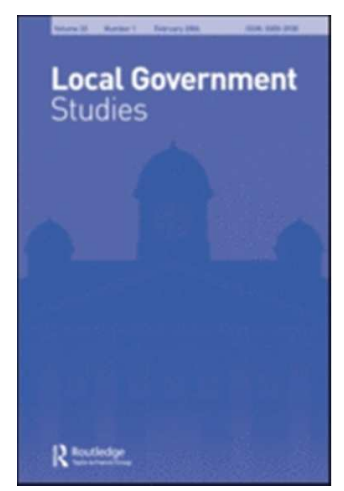

\title{
Dealing with Austerity: a Case of Local Resilience in Southern Europe
}

\begin{tabular}{|r|l|}
\hline Journal: & Local Government Studies \\
\hline Manuscript ID & FLGS-2016-0160.R1 \\
\hline Manuscript Type: & Review \\
\hline MS Keywords: & $\begin{array}{l}\text { austerity measures, economic crisis, local government resilience, } \\
\text { institutional adaptation }\end{array}$ \\
\hline \multicolumn{2}{|l}{} \\
\hline
\end{tabular}

SCHOLARONE ${ }^{m}$

Manuscripts 


\title{
Dealing with Austerity: a Case of Local Resilience in Southern Europe
}

\author{
Lluís Medir, Esther Pano, Alba Viñas and Jaume Magre \\ Department of Constitutional Law and Political Science, University of Barcelona, \\ Barcelona, Spain
}

CONTACT Lluís Medir lluismedir@ub.edu University of Barcelona, Department of Constitutional Law and Political Science, Avinguda Diagonal 684, Barcelona, Catalunya 08034, Spain

\begin{abstract}
Southern countries are undergoing a severe economic crisis that has renewed debates about the available strategies to economize their public resources. Political leaders have launched a wide range of different strategies aimed at reducing spending. According to generally accepted political discourse, drastic actions should be taken to guarantee economic and financial sustainability in times of austerity.
\end{abstract}

We explore the main measures adopted by Spanish municipalities in order to examine their impact in budgetary terms. First of all, we identify the most frequently implemented mechanisms including organizational structure, public services and operational economic restructuration. After their quantification, we monitor the presence and impact of each set of policies to analyse the relationship between concrete measures and effective economic impact.

The effective reduction of budgets is being implemented but data shows that local governments are resilient to non-compulsory changes. The 'government at a distance' policy pursued by the central state administration has effectively 
reduced budgets but has not affected the institutional core of Spanish local governments.

Keywords: austerity measures; economic crisis; local government resilience; local restructuration.

\section{Introduction}

Europe and particularly the southern countries are undergoing a severe economic crisis that has renewed debates about the available strategies to economize their public resources in order to reduce the deficit. Pushed by the European Commission, the IMF FMI and the European Central Bank, some of the southern European Member States have promoted policies of austerity and spending cuts at the local level (Di Mascio \& Natalini, 2015). In some cases, these fiscal policies have attempted a profound transformation of the municipal structure and organization (Greece, Italy). However, in other cases (such as Spain and France) the basis of the municipal structure remains untouched in exchange for the incorporation of economies of scale into public service management, and the imperative to reduce public debt and to implement effective budget equilibrium. Under this framework, an explanation of how, and with what effects, budget cuts at the local level are undertaken gains special relevance. A basic understanding of the effects of this new fiscal situation imposed from upper-tier governments on local structures is the main purpose of this work.

Even if local governments are not the main source of public debt and fiscal stress in Europe, central and regional governments have required them to commit to reducing costs and implementing measures to reduce their public expenditures.

In Spain in 2011, after three years of public budget instability in the very heart of the financial crisis, fiscal austerity achieved constitutional status when the amendment of 
Article 135 of the Spanish Constitution placed budget stability and the repayment of loans subject to debt interest as constitutional priorities. This constitutional protection of austerity gave birth to several laws devoted to fiscal austerity and budget stability, which affected all public institutions. Since then, two main bills that affect local finances were passed with the objective of addressing the structural reforms demanded by the EU mainly through the approval of Law 2 /2012, of 27 April, on Budget Stability and Financial Sustainability, and the LRSAL (Law 27/2013, of 27 December), which is a reform of the Local Act amending the legal framework established by Law 7/1985. The Spanish case is extremely interesting because reforms are mainly driven by introducing restrictions on local finances rather than by structural reorganization, as is the case in Greece, Portugal and Italy.

The institutional position of Spanish local governments in the political system is characterized by their belonging to the so-called 'Franco or Napoleonic' group of local governments, mainly located in the south of Europe (Heinelt \& Hlepas, 2006). This group of local government systems is characterized by a high level of political autonomy and elite bargaining capabilities, but with low functionality — which is to say, low performance in terms of output production (John, 2001; Page \& Goldsmith, 1987; Wolman \& Goldsmith, 1992). This southern group, originally formed by Spain, France, Greece and Portugal, seems to cling mostly to the idea of a strong local representative elite and a centralized bureaucracy. The political expression of local autonomy, together with the generalized lack of capabilities and resources, faces us with a constellation of strong political institutions with narrow margins for real manoeuvre, and with low or very moderate economic impact in aggregate terms. By contrast with the 'NorthernMiddle European' typology, local governments in Southern Europe have neither the opportunity to increase their income by levying and increasing their own taxes nor the 
possibility of determining substantially which tasks have to be fulfilled, because they are very financially dependent on regional or central government.

Due to the unprecedented gravity of the economic crisis, local governments have been subjected to political pressure, coming mainly from the central state, to place budget reductions and fiscal consolidation at the top of their agendas. Therefore, mayors and local staff have begun a race against budget imbalances that are blamed on excessive spending. This political pressure has promoted municipal savings on public budgets, achieving an average spending reduction of 459 euros per capita in Catalan local governments from 2009 to 2013 , according to our data.

The main objective of this article is to understand the impact of the austerity measures implemented by the sole will of local authorities in their budgets. For tackling this objective, we firstly identify the concrete measures undertaken by a large sample of local governments in Spain in order to, secondly, test the concrete impact of the implemented measures on local budgets. Therefore, this article aims to identify and classify the concrete measures implemented, on the one hand, and whether they have had an impact in budgetary terms and under what conditions, on the other. Moreover, the research on budget decisions links naturally to organizational impact and institutional design since local institutions modify and restructure their functions by changing their budget priorities.

To test the existent relation (if any) of implemented austerity measures in local budgets, we build an 'Austerity Measures Index' (AMI) as an instrumental variable in order to quantify and equalize the concrete measures implemented at the local level and to test their impact on public budgets. Taking Catalan local governments as a case study, we want to make an empirical assessment of the real impact of austerity measures on local 
budgets. Catalan municipalities are a good testing ground for Spanish and Southern European municipalities since they fulfil all of the characteristics belonging to the 'Franco type', widely described in the literature.

The article is organized as follows. Following this introduction, we briefly present the basic literature regarding crisis and expenditure patterns in local governments. The third section presents the research question and its translation into two main hypotheses for testing, together with a presentation of the data and methodology for building our AMI. The fourth section is based on descriptive statistics and it identifies the most frequently implemented mechanisms on structure, reorganization of the public services (both from the input, as well as the output perspective), and operational economic restructuration. The fifth section presents the main results based on the determinants of our AMI, and the relations between our index and the effective budget impact. We finally present a discussion and some brief conclusions.

\section{Local budgets and austerity measures in times of fiscal crisis}

A wide range of theoretical elements needs to be considered in respect of the introduction of austerity measures at the local level. First, it is useful to address some general ideas concerning the concept of crisis and its implications. If crisis is conceived as a moment of transformation and decisive political intervention (Hay, 1999, 2013), we also need to consider some elements related to the existing theory on cutback management and austerity measures. In a second step, for a complete empirical assessment of the impact of economic crisis and austerity in local governments, we need to take into account elements coming from the institutional and organizational structure of municipalities, together with cutback management, and contextual elements that shape local structures (Overmans \& Timm-Arnold, 2015). 
There is no dominant concept to be found when defining crisis (Orr, 2009). Some authors describe the concept of crisis as one of the most undeveloped concepts in social and political theory (Hay, 1999; Orr, 2009). However, it is possible to identify it as a moment (or a continuity of moments) in which a decisive intervention is made in order to redress organizational dysfunctionalities. This capability to redress critical situations differs along an ideal continuum that has 'dynamic and proactive systems' (based on organizational learning and ability for managing change and self-transformation) at one extreme, and 'inertial and re-active systems' at the other (Hay, 1999). This is to say, reactions to these stressing situations for public organizations of all levels vary among 'denying or delaying cuts' or 'implementing cuts' as instruments, and strategic or 'equal misery' approaches to solve problems, the literature already accounting in different manners for such basic distinction (Overmans \& Noordegraaf, 2014; Pollitt, 2010; Raudla, Savi, \& Randma-Liiv, 2013)

Therefore, we can identify systemic versus conjectural austerity strategies at any governmental level. The former can be conceived as a response to systemic failures, where institutions are fundamentally transformed. The latter is a response to systemic failure in which a solution is sought within the pre-existing and unmodified structures (Hay, 1999). This is to say, we can easily differentiate between strategies that affect core functions of political institutions, from superficial strategies that rely on minor or cosmetic changes. In general terms, Hay (1999) offers four strategic responses that can be categorically classified, from stronger to lighter:
a. Responses to resolve the failures in their totality.
b. Responses to resolve selective contradictions and failures.
c. Responses to resolve the narrative of the crisis.
d. Purely discursive responses. 
Applied specifically to the local level, these four categories of strategic responses to the 'symptoms' of crisis imply different institutional effects. The first is almost impossible to observe at the local level, as local governments are mostly 'creatures of the state'. This institutional position practically implies their lack of capacity to implement effective measures to solve the totality of the crisis. In the same line, Pollit (2010) argues that highly fragmented systems may find it more difficult to undertake overall strategies. Generally, local governments' responses imply dealing with decisions from the upper tiers of government. So, theoretically, when facing local governments' decisions on austerity measures and crisis symptoms, our theoretical expectations would seem to range from responses basically to fight against the narrative of the crisis, through symbolic and discursive decisions, to purely discursive responses, rather than addressing structural cutbacks, as it has also been pointed out in Overmans and Noordegraaf (2014). In any case, austerity management can be defined as: 'executive and managerial responses, aimed at restoring the fiscal balance, against the background of increasing demands for [public] services and [political and public] expectations of organizational performance' (Overmans \& Noordegraaf, 2014, p. 101).

Linked with these possible responses to fight against economic crises, considerable discussion has recently taken place about the resilience of local governments and their ability to adapt in a changing environment (Lowndes \& McCaughie, 2013; Shaw, 2012). Assuming this new trend, resilience can be viewed as the ability to change rather than the ability to continue doing the same thing (Shaw, 2012). Under this approach, local governments are, by nature, the more flexible and innovative institutions with clear strategic leadership and the ability to change and to adapt. So, together with the austerity strategies, the introduction of austerity measures at the local level can also be 
analysed as a 'resilience strategy' where budget cuts might be addressed but with a view to change within institutional preservation.

\subsection{The politics of austerity in troubled times}

In an era of permanent austerity (Pollitt, 2010), the question of dealing with management cutbacks in public organizations is at the forefront of most organizations and practitioners. Therefore, a growing interest in understanding and classifying responses to financial crisis appears. We summarize in this section the main vectors of classification for austerity measures, together with their implications in organizational terms. Recent reviews from Raudla et al. (2013) and Overmans and Noordegraaf (2014) summarize the main findings related to cutback strategies, patterns of cutting expenditures and the changes occurring in decision-making processes of public organizations.

For cutback strategies, a usual dichotomization of the main possibilities appears in Raudla et al. (2013): 'across the board' versus 'targeted cuts' reveals the main divide. In fact, this is a classic distinction that is generated in function of the impact of decisions on budgets and services: where a strategic approach is put forward on 'targeted cuts', and an 'equal misery' decisional approach is emphasized on 'across the board' or salami-slicing decisions. Concerning the instruments to implement cuts, the theoretical variety being wide, again Raudla et al. (2013) establish a tripartite taxonomy: instruments for cutting operational measures (running costs), programme measures (transfers and grants) and capital expenditures (investments). Inside each category, they identify a large typology of concreate measures, ranging from cutting personnel to laying off personnel in cutting running costs; to reduction of capital expenditures and reducing cost services provision for programme measures and investments. Finally, they 
depict how these cutback strategies and instruments run into organizational effects. They argue that changes in public management practices reflect the need to adapt internally and externally to the environment, emphasizing the centralizing tendencies, but also the local resilience, in the relations between national and local government (Raudla et al., 2013, p. 28).

Overmans and Noordegraaf (2014) offer a theoretical model elegantly built on two dimensional axes to analyse both the effects and types of austerity measures. They argue that managing austerity can mainly be analysed through a continuum of two independent axes: one axis is focused on the stability (superficial reduction) or change (proactive and long-term viability) of the organization, while the other focuses on the type of measures, being purely fiscal or affecting organization structures and systems. This theoretical model opens up into a two-by-two table, for theoretically generating four different types of responses to austerity: Decline, Cutbacks, Retrenchment and Downsizing.

In their work, Overmans and Noordegraaf (2014) identify Decline as a kind of organizational measure showing a passive managerial reaction, primarily focused on stability: ending policies, reducing levels of maintenance, decreasing support, among others. Cutbacks are also focused on stability, but include fiscal measures, such as cheese slicing cuts or cuts-across-the board, with the objective of driving the organization to lower levels of resource consumption and lowering activities. Retrenchment is a proactive response mainly focused on fiscal change and it may include measures such as raising fees and taxes or adjusting actuarial rates. Finally, Downsizing is described as a 'strategy for improving organizational performance and restoring organizational-environmental fit', and may include measures such as optimizing work processes and costs or organizational efficiency. Although a clear 
conceptual divide emerged from these four possibilities, this classification should be considered 'as a continuum rather than completely separate categories' (Overmans \& Timm-Arnold, 2015, p. 7), because usually measures combine several objectives and instruments.

Summing up, an intention can always be found when applying austerity measures, and there is usually some room for manoeuvre when it comes to managing austerity measures at any political level. Most of the time, the choices to be made involve a strategic way of reasoning, since we have to retain the fact that local responses to crisis and austerity are mediated by politics, since local elected politicians need to solve a permanent tension between cutbacks and public service provision.

As we have established, management cutbacks in public organizations are a consolidated topic of research, nevertheless, recent interest is growing in the relationship between local governments and austerity measures at the local level. In fact, municipalities appear as an important site from which to explore crisis and institutional change (Cepiku, Mussari, \& Giordano, 2016; Keller, 2014; Orr, 2009; Overmans \& Noordegraaf, 2014) mainly because local institutions are extremely sensitive to direct expressions of crisis given their proximity to citizens and communities. Indeed, the subnational level allows better comparability as politico-administrative variables and legal restrictions operate in a homogeneous way in every country or region considered, with potentially large-N units analysis.

\subsection{Austerity measures at the local level: specificities and context.}

If management literature has treated vastly the question of classifying and evaluating austerity measures, less attention has been devoted to their effective implementation and 
impact at the local level. Most of the works are based on states and regions and, specifically to municipalities, mainly in US cities - and to a less extent UK cities (Overmans \& Noordegraaf, 2014, p. 103; Raudla et al., 2013, pp. 4, 39 and appendix for a detailed summary). Some recent studies treat European municipalities, with small samples of cities being observed in detailed case-studies, but mainly addressed to a better understanding of the types of measures and the determinants of their choice (Cepiku et al., 2016; Keller, 2014; Ladner \& Soguel, 2015; Overmans \& Noordegraaf, 2014; Overmans \& Timm-Arnold, 2015).

These seminal works, together with other related literature, offer a basic understanding of the variables potentially affecting austerity measures at the local level. However, not sufficient straightforward evidences are available when analysing local governments' behaviour in managing austerity (Cepiku et al., 2016, p. 229; Raudla et al., 2013, pp. 9, 30, 39). In fact, Overmans and Timm-Arnold (2015) clearly state that their findings 'do not support the concept of universal austerity plans. Instead, they indicate a relation between the institutional system and the deployed responses'. Therefore, a large effect of institutional and contextual factors is present when analysing local governments in austerity times. Most of the variables related to the political-administrative system relate to socio-economic forces, financial situation, strength of the executives and others related to the administrative culture (or structure) (Overmans \& Timm-Arnold, 2015, pp. 3 to 5$)$.

Since public budgeting is the process of macro-allocation of resources coming from the central state, at the local level we are facing a process of micro-allocation where tough choices must be made among a huge number of competing programmes. There is also at the local level a general tendency to accept the allocation of the previous year as a given, and to examine changes from that allocation: 'the budgetary process itself 
appears to push toward incrementalist outcomes, even in economic environments that appear to call for "rational decrementalism"” (Peters, 2010). Indeed, when turning attention to the specific field of public budgeting, it is widely accepted that 'There are striking regularities in the budgetary process' (Davis, Dempster, \& Wildavsky, 1966). These regularities are based on the fact that a given budget approved in year $t$ is highly dependent on the one approved in year $t-1$ (Natchez \& Bupp, 1973). In fact, the fundamental factors in the budgetary process tend to work along the lines of incremental outcomes; first, in terms of the technical and sheer magnitude of the process itself and, second, in the sequential and repetitive nature of budgeting. In this sense, our approach to budget change is rather simple: we understand change as the increase or decrease in the budget of our localities.

Regarding the ability to manipulate public spending, the capacity of incumbents in local governments for introducing cycles on local budgets has been widely accepted (for an intensive review see Benito, Bastida \& Vicente, 2013). From this assumption, incumbents manipulate economic activity in order to increase their chances of being reelected. Cycles are strongly related to elections. Usually, the opportunistic behaviour of incumbents appears when government spending increases, deficits increase, or tax cuts are implemented before elections.

Thus, under conditions of extreme austerity and social cuts, an ideological explanation for the implementation, or not, of austerity decisions might also be plausible. The ideological dimension is easily captured by the left-right scale that offers a progressive and redistributive view of the role of the state against a more conservative and market oriented state outlook. This left-right scale taps into economic issues associated with the redistribution of wealth, taxing and spending, and the role of the state in the economy, and has been used in previous studies (Karyotis, Rüdig \& Judge, 2014; Overmans \& 
Noordegraaf, 2014, p. 103; Raudla et al., 2013, pp. 20-21). However, it has never been proved as a clear predictor of almost any municipal behaviour, especially regarding economic issues (Bastida, Beyaert \& Benito , 2012; Benito, Bastida \& García, 2010). In any case, as the austerity programme launched by the Spanish government was backed and designed by the conservative parties, we have considered that this might be a relevant factor in explaining the differences in the number of measures implemented.

In addition to the form of government and its implications, there is also a growing literature, linking expenditure and type of government, typically, majority vs coalition governments (Bastida et al., 2012). These approaches indicate that majority governments tend to fall into lower levels of debt and, therefore, better control spending. Indeed, given that in any quasi-parliamentary system political and party performance is characterized by a strong alignment of votes between party leaders and elected members, we consider that mayors of single party governments, with a higher share of elected officials, may face fewer problems in adopting these kinds of measures. Therefore, powerful mayors will implement more measures, following the central political mood, than less powerful mayors (coalition or minority mayors).

Regarding socio-economic aspects, the economic level of the municipalities, measured through average GDP per capita, has also been used as a proxy for the wellness of the city (Bastida, Benito \& Guillamón, 2009). Unemployment at the municipal level may also be considered as a relevant variable, although its impact on budget cuts is far from evident. We hypothesize that higher levels of unemployment will lead to lower scores on AMI, assuming a sort of 'protection' from austerity for vulnerable citizens.

Population and density are also usual control variables in any local government study. Population usually matters and, in this case, we wanted to explore if it really does 
matter and, if so, how. The general assumption of the impact of population presumes that large cities, with a higher budget and greater room for manoeuvre, may adopt more austerity measures. Density is a predictor for the existence of economies of scale, making it easy to reduce costs or increase savings. Moreover, a mayor of a large city can easily apply more austerity measures as he/she is more distant from the citizens than is the case in small or medium local government.

\section{Hypotheses and data}

To answer our two basic objectives (identification of austerity measures, and their impact in budgetary terms) we provide two types of evidence. On the one hand, we offer in section four a detailed panoply of the austerity measures implemented by Catalan local governments, together with their operationalization through AMI. On the other hand, in section five, we address the question of their economic impact in local budgets.

Given the decremental reality of the budgets of local governments in Catalonia, we want to test two simple hypotheses concerning the second objective. The first aims to identify the basic determinants of the implementation of austerity measures at the local level: Under what conditions do local governments implement austerity measures? The second hypothesis aims to test the impact of those austerity measures on local budgets. The concrete formulation of the hypotheses is as follows:

\section{H1. Larger and more complex cities may apply more austerity measures (the greater the values of AMI).}

That is to say that the determinants of AMI are related to a group of relevant sociopolitical variables (which add complexity to local governance). We attempt to find 
higher scores of AMI in larger, denser, less politically fragmented, and right-wing cities than in others. Since the Franco type typology implies a homogenization of local governance, we will focus on $\mathrm{H} 1$ in variables that present higher variability across units. These variables, and their disparity, are generally conceived as the only ones that allow Southern European local governments to differentiate among themselves in relation to policy-making.

\section{H2. The higher the score on the AMI, the higher the budget reduction.}

Applying more austerity measures should generate a higher impact in budgetary terms. In this case, we are addressing the core assumption of the paper. Does the adoption of austerity measures make any difference at all or are they mainly rhetorical? That is to say, is it the case that the more measures undertaken (measured from AMI), the greater the budget reduction? We must assume that the answer is yes, that the higher the AMI score, the deeper the budget cuts at the local level.

\subsection{Methodology and timing details}

Given that there is no available official information, in order to study the implementation of austerity measures we are using information taken from the Project Observatory of Local Government, conducted by the Fundació Carles Pi i Sunyer. All Catalan municipalities of more than 500 inhabitants - those with an effective political and administrative room of manoeuvre - except Barcelona, are included in the study, for a total $\mathrm{N}=625$. The fieldwork was conducted from September to December 2013. As for the budget data, we are using data gathered by the Spanish Ministry of Public Administration.

As the study was supposed to cover a period of time that includes the situation previous to the deepest impact of the economic crisis, the process of decision-making and 
implementation of measures, and the impact in budgetary terms, three different moments, could be identified in the methodological strategy:

(1) Budget for 2009 (in terms of budget out-turn according to the Spanish public accountancy system). This budget was developed in a previous period to the implementation of the austerity measures. It could be said that it was still configured as a budget within a framework of expansion or the start of deceleration but still no stagnation or crisis. We have opted for this precise period as it could be considered as the last one prior to the crisis and it offered advantages in terms of population equivalences.

(2) Field work. The questionnaire included questions about the measures included in the 2013 budget.

(3) Budget for 2013 (in terms of budget out-turn according to the Spanish public accountancy system). This budget should reflect the impact of the austerity measures (available December 2014).

\subsection{Operationalization and main variables}

The questionnaire on austerity measures included a group of questions related to their implementation, and it was organized following the theoretical impact of every measure in the local budget, ranging from structural measures to contingency measures.

However, we adhere to the Overmans and Noordegraaf classification (2014), since it allows to better contrast our results with the theoretical expectations behind every measure in the final discussion.

As regards measures responding mainly to 'cutback' responses (that is fiscal measures of a stable nature), we include:

- Reduction in the amounts paid for attendance at meetings (compensation of expenses) 
- Reduction in elected members' salaries

- Reduction in overtime payments

- Reduction in representation allowances

- Changes in Compulsory services:

- Public street lighting

- Waste collection

- Street cleaning

- Paving and maintenance of streets and roads.

As regards measures relating to Decline (that is to say, with organizational impact and tending to stability), we identified:

- Reduction in the number of civil servants

- Reduction in the number of other staff members

- Strategies designed to reduce energy consumption

- Reductions in funds for investments.

In the category of Retrenchment, that is measures focusing on change and of a fiscal nature, we identified changes in all non-compulsory services:

- Non-compulsory services

- Emergency social services

- Public transportation

- Housing services

- Libraries

- Social and cultural centres, and museums

- Public sport facilities

- Childcare

- Adult education 
- Music schools.

Finally, in the category of Downsizing, that is to say the determination of a set of intentionally and coherent measures, we monitor the existence of a comprehensive Austerity Plan in the municipality.

We also included general descriptors of the municipality, including population and territory, and political variables such as the political affiliation of the mayor, political strength, and the type of government (majority, coalition or minority). We recoded the original party affiliation of mayors to a dichotomous left-right variable. We measured the strength of government as the percentage share of elected officials belonging to the mayoral group among the total of elected officials. Finally, we created a dummy variable to capture coalition governments (more than one party) against the others (majority and single minority governments), assuming that coalitions face more problems to agree on austerity decisions due to the double bargaining process to be approved (first in the local executive and then in the city council). To avoid cycles, we designed a variable to compare the evolution per inhabitant from 2009 to 2013, as they represent two mid-term budgets, otherwise, the gross amount and pre-electoral or postelectoral budgets would introduce enormous biases.

\subsection{Building the Austerity Measures Index (AMI)}

In order to work with these variables, we needed to define a mechanism to quantify the austerity measures taken by every city council. We opted to operationalize the general concept of austerity measures into the proposal for an 'Austerity Measures Index' (AMI) that allows us to create an aggregative indicator scaling the number and relevance of the strategies adopted. 
AMI is constructed using a calculation based on all the declared austerity measures in every local government (from 0 to 24 possible measures). To create a homogeneous indicator, the index has been reduced to a 0 to 1 scale and weighted in order to distinguish the different impacts of the different measures. The weights respond to the need to compensate the different economic impacts that every type of measure has in the local budget, since undertaking a reduction in energy consumption is not the same as reducing the number of staff members. So, the proposed weights are grounded on the average percentage representing each measure in local governments' budgets over the years.

Measures affecting structure into the long term: all measures weighted 0.4.

Measures on public services delivery: all included services weighted 0.35 .

Contingency measures: all considered contingency measures weighted 0.25.

Table 1 accounts for their assigned weight and theoretical classification, together with their use across municipalities. Our instrumental variable AMI serves us to first, test the socio-political determinants of AMI; second, using the index as an independent variable, we explore its relation to austerity in local public budgets. Both issues will be addressed using OLS regression techniques.

\section{Descriptive statistics}

This section shows the large and raw numbers related to the identification and use of austerity measures. We show whether local governments have or have not undertaken austerity measures in concrete terms, leaving aside the precise type of measure.

Although we have this information for most of the services, our preliminary aim is to detect where (in which services and topics) austerity measures are being implemented. 
We now present the results of the Survey. Regarding the implementation of all kinds of measures, respondents have identified the following actions:

\section{Table 1}

We comment on the results in Table 1 following the impact of measures on local budgets. It shows that, on average, we found austerity measures on structural aspects in $40 \%$ of local governments. Political aspects, such as reductions in salaries of elected members and amounts paid for attendance at committees or institutional meetings, were reduced in most of the cases $(65.1 \%$ and $56.1 \%$ respectively). These are immediate and visible measures that can be easily perceived and understood by citizens. However, in budgetary terms, they cannot be especially relevant. Concerning the reduction of staff, it is important to notice that the reduction comes mostly from staff members $(46.3 \%)$ rather than civil servants (only 19.2\%), the latter being much more difficult to reduce because of the life-long nature of their positions. Finally, it was quite unexpected to find that only $9.8 \%$ (53 out of 563) of local governments in Catalonia decided to implement such a general plan.

Concerning measures on public services, here we expected to find different and wider measures as there are some compulsory services by law, and others based mainly on local self-government and political will. As for non-compulsory public services, we took into account the fact that the levels of service provision may differ, as they are not guaranteed by law. The preceding Table 1 shows that the most affected services are, in fact, those directed at children, childcare and music schools.

The final set of measures includes strategies intended to have an immediate impact (contingency measures). In general terms, we could say that the number of municipalities adopting these kinds of measures is high. Special attention should be 
given to strategies to reduce energy consumption in that more than $85 \%$ of respondents answered affirmatively.

The picture emerging from Table 1 already shows that most of the austerity measures are rolling towards stability, and most of them fiscally oriented. Therefore, part of the theoretical arguments stating that local governments will tend more naturally towards stability and discursive responses may have some room. Indeed, the situation of all measures in the theoretical model already indicates a sort of general tendency for municipalities to adhere to stable and 'conservative' decisions, rather than engaging in deep restructuration. We have to enrich, though, this analysis through a more complex approach including an aggregative measure, such as AMI.

Regarding AMI, as it is an aggregated index of the aforementioned austerity measures, it is useful to address some basic bivariate statistics to analyse its behaviour. In this respect, Table 2 shows the main descriptive information for the AMI, which is scaled from 0 to 1 . It should be noted that a score of both 0 or 1 , although materially possible, is highly improbable. The mean is set at 0.377 in a quite close position to the median.

Table 2

We also launch some bivariate exploratory analyses in order to learn more about our variables, especially when related to size and budgetary impact. First, we test the impact of population size on the AMI, as it has been empirically shown to be a fundamental explanatory variable at the local level. Second, we test the effect of our AMI on the change in local budgets from 2009 to 2013.

Figure 1 takes AMI on the vertical axis and population (logged to avoid disrupting effects) on the horizontal one. The regression line is the central one, and the external 
lines represent the $95 \%$ confidence interval. The figure clearly shows that there is a positive correlation between the increase in AMI and the increase in population. That is to say, the AMI is sensitive to the size of the polity in which it is calculated. In order to better assess the intensity of this bivariate relation, the results of a simple Pearson correlation show a significant and moderate positive correlation between the AMI and population (Coef. 0.440; Sig. 0.000; N=393).

Figure 1

Following with the bivariate approach, we analyse the other side of our AMI through the main variable we want to explain: change in local budgets. Once stated that there is a relation between size and AMI, we explore the relation of AMI and budget change. In

Figure 2, we run a correlation between the cuts in public spending and the values of AMI. The results are quite clear: in a bivariate model there is no clear impact of AMI on the decrementalism of local budgets. From this relationship, we are unable to observe a pattern of clear decrease in local budgets when more austerity measures are being implemented.

Figure 2

Although these results of the AMI variable might seem contradictory or conflicting, in fact they show that we are facing a strategic institutional choice. Since large municipalities have greater responsibility for more aspects of the everyday life of citizens, that is to say, they hold more competence, they have more room for manoeuvre and for the implementation of austerity measures. However, whether the city is large or small does not have a differential impact among municipalities when effective budget reduction per capita is considered. The institutional choice made is plausibly linked to 
strategic reductions in the budget and not responding to the need for effective budget reduction, rather than on the political claims associated with the political mood of implementing reforms and cuts.

Finally, Table 3 includes some descriptive statistics about budget information. The general pattern is a strong reduction in expenses over four years. The data for inhabitants show an average reduction of $459 €$, representing almost $30 \%$ of the mean of the value for 2009 .

\section{Table 3}

\section{Results}

As politics and policies are not driven in a bivariate world, we launch two OLS multivariate regressions in order to test diverse impacts of different sorts of variables. Notice that in $\mathrm{H} 1$ we use our AMI as the dependent variable, whereas we use the budget reduction per habitant from 2009 to 2013 as a dependent variable for $\mathrm{H} 2$.

Regarding H1, we stated that larger and more complex cities might apply more austerity measures (the bigger the values of AMI). We run two regression models to assess the impact of a first group of socio-economic variables (model 1), and to add political variables in model 2 . The results are shown in the following tables.

\section{Table 4}

The results of model 1 partially confirm the expected effects of population (logged) over AMI when controlling for other socio-demographic elements: the larger the city, the higher the score on AMI. Indeed, we find a significant coefficient on 'Per capita debt 2013', indicating that the financial situation of the municipality has a positive impact on the decision to take austerity measures. Model 2 maintains the explanatory 
power of both variables: population and debt. However, the remainder of the political variables are not significant to understanding the scores of AMI. This is to say, austerity measures seem to be related to the fiscal situation of the locality, affecting then the number and extension of measures implemented.

The core of this paper intended to test the impact of AMI on budget reduction, therefore H2 stated that the higher the score on AMI, the higher the budget reduction. In this case, again, we run two regression models to assess the impact of a first group of socioeconomic variables (model 1), and add political variables in a second step (model 2). We propose a multivariate model taking into account the combined effects of several independent variables on the change of per capita spending from 2009 to 2013, some of them not tested up to this point.

As we want to test the influence of the AMI, we do not take into account other independent variables that highly correlate with it, such as population or debt. Instead, we make a calculation on the evolution of relevant variables, keeping in mind that our dependent variable is the per capita budget evolution from 2009 to 2013, in absolute euros. We add some proxy variables to test other aspects of local reality: we take as a proxy of local wealth the mean in the revenue tax at the municipal level for 2009. Results are shown in the following table.

Table 5

Our results show that for model 1 , there is no explanatory variable for the change in local budgets: none of the socio-economic variables proposed are shown as statistically significant. These results seem to reinforce the idea that cuts are not economically or socially driven, but politically determined. Basic socio-economic variables of local governments do not seem to guide the implementation of austerity measures. At first 
sight, the decremental nature of local budgets is not affected by socio-economic variables, leaving room to more complex models: this result impels us to add political variables to the analysis.

Regarding model 2, which adds political variables, our results show two important findings. On the one hand, there is only one statistically significant coefficient: the strength of local government, measured as the percentage share of elected officials belonging to the mayoral group among the total of elected officials. Nevertheless, its impact in real terms is quite modest: each increase in one unit in the strength of municipal government (in \% of seats belonging to the mayoral group) explains a decrease of almost 7 euros per capita in our dependent variable. That is to say, the stronger the mayoral support in the council, the deeper the economic cuts can be. On the other hand, AMI does not appear as significant in our model. This result seems to indicate that we cannot explain the budget cuts from the amount of austerity measures implemented by local governments. This data seems to accept the considered null hypothesis, thus rejecting the notion that applying more austerity measures generates a higher impact in budgetary terms. This result may indicate that we are facing cosmetic measures in order to react to general political discourses, rather than addressing fundamental changes.

\section{Discussion}

One of our objectives was to reflect on the way that local governments face economic crisis, using their margins of manoeuvre by implementing austerity measures. Previous theoretical studies have shown the difficulty, or impossibility, for local governments to address effective responses to systemic crisis. When the full range of theoretical responses to crisis was considered (Hay, 1999), we had already circumscribed the local potential to fight against crisis mainly by acting against their own narrative, through 
symbolic and discursive decisions, or with purely discursive responses. Also Overmans and Noordgraaf (2014) find similar patterns, since they find that despite political ambitions tending to be innovative and modern, municipal executives 'commonly concentrate on safe measures with short-term budgetary wins and minimal public opposition' (p. 105).

In this sense, most of our results confirm these theoretical explanations. Our sample of local governments undertook identifiable and concrete austerity measures. However, the impact of these measures for understanding the decrementalism of local budgets is far from evident. We found that a relevant number of measures were implemented at the local level in 2013. We identified a range of different measures and we classified them into four basic strategies and assessed their influence depending on their impact on local budgets (structural cuts, reductions related to public service delivery, and contingency measures).

The empirical strategy of assigning different impact-weights for every single measure has also been proved as congruent with previous theoretical explanations. Our empirical findings are in line with recent literature on austerity measures of local governments. These previous findings (Cepiku et al., 2016; Ladner \& Soguel, 2015; Overmans \& Noordegraaf, 2014; Overmans \& Timm-Arnold, 2015) already highlighted that there is a tendency to perceive reforms as mere straight cutbacks, provoking mostly 'conservative' reactions in municipal executives without strategic approaches.

Our data seem to confirm that local political elites in Napoleonic models also react, in the first instance, by focusing on stability and safe measures, with minimal political cost. These results still need to be tested on similar local government systems, but since politico-administrative traditions are a strong modulator of elites' reactions, the 
homogeneous nature of Napoleonic systems offers chances to find similar results. Our study can offer new insights and new methodologies to test the impact of austerity measures on a given state or region, and with large-N configurations.

\section{Conclusions}

When testing the nature and determinants of AMI, similar 'conservative' effects appear. The bivariate analysis results show a particular behaviour of AMI: although it increases when analysed in relation with city size, it shows no relation to budget reduction. This clash of results seems to indicate a pattern of strategic institutional choice: the adoption of austerity measures could be mainly rhetorical, as larger cities apply more measures, but general impacts on local budgets do not increase with higher values of AMI.

These findings seem to be reinforced by our multivariate analysis. With respect to the determinants for implementing more or less austerity measures at the local level (to explain AMI values), we found that size and debt are good predictors for the implementation of austerity measures. These results are coherent with our bivariate analysis and add the idea of the need for more indebted local governments to show more political engagement with budget cuts. Moreover, our OLS regression model, devoted to explain effective budget reductions per capita, does not provide evidence to consider AMI as a relevant variable to understand decrementalism in local budgets. Our results in model 2 reject the fact that applying more austerity measures generates a higher impact in budgetary terms, showing that implementation at the local level can be mainly a discursive response from local elected politicians to economic crisis.

Political claims and empirical data confirm the existence of a reaction from local governments when externally obliged to implement budget reductions. However, the policy implications are clear: local governments introduce a varied and wide range of 
measures, but without clear impact in budgetary terms. Nevertheless, budget cuts are real but are not determinants to an understanding of institutional change. In other words, the selective cuts and measures implemented by local governments seem to cling to the basic idea of 'plus ça change, plus c'est la même chose'. When local governments in southern European countries are obliged to react, but are allowed wide room for manoeuvre, the changes they propose do not challenge the core functions of local institutions, nor do they address drastic changes in organizational performance. Local governments react by protecting the institutional hearth, focusing on organizational stability, and by throwing out discursive decisions and responses to weather the storm, probably waiting for the renaissance.

\section{Acknowledgements}

The authors are grateful for the comments made to previous versions of this work by the participants in the 2015 ECPR Joint Sessions in Poland and the EGPA 2015 in Toulouse. We also acknowledge the comments made by department colleagues in our research seminar. As a final step, we recognize the huge improvements made to the paper with the comments of two anonymous reviewers. This work was supported by the Spanish Ministry of Economy under Grant CSO2013-48641-C2-2-R; and AGAUR, Catalan Government, under Grant SGR-838.

\section{Disclosure Statement}

No conflicts of interest are present.

\section{Notes on contributorws}

Lluís Medir lectures in the Department of Political Science at the University of Barcelona, Spain. His research interests include local government and public policy, and his most recent publication is "Patterns of gender representation in councils at the second tier of local government" in Policy Making at the Second Tier of Local Government in Europe: What is happening in provinces, counties, départements and landkreise in the ongoing re-scalling of stathood? ed. Xavier Bertrana and Björn Egner, Routledge, 2015. 
Esther Pano is the project coordinator of the Local Government Observatory at the Carles Pi i Sunyer Foundation, and an associate lecturer at the University of Barcelona, Spain. She is the author of "Cambios en la escala y gasto: una aproximación a los servicios de bienestar comunitario en los Ayuntamientos de la Comunidad de Madrid”, in Anuario de Derecho Municipal, 2013.

Alba Viñas is a researcher at the Carles Pi i Sunyer Foundation, Barcelona, Spain. She is the author of "Cambios en la escala y gasto: una aproximación a los servicios de bienestar comunitario en los Ayuntamientos de la Comunidad de Madrid", in the Anuario de Derecho Municipal, 2013.

Jaume Magre is a professor at the University of Barcelona, Spain. He is Director of the GREL research group on local studies and Director of the Carles Pi i Sunyer Foundation, and his research interests include local government and electoral systems. His most recent publication is "Moving to suburbia? Effects of residential mobility on community engagement", Urban Studies, 2016.

\section{References}

Bastida, F., Benito, B., \& Guillamón, M.-D. (2009). An Empirical Assessment of the Municipal Financial Situation in Spain. International Public Management Journal, 12(4), 484-499. http://doi.org/10.1080/10967490903328139

Bastida, F., Beyaert, A., \& Benito, B. (2012). Electoral Cycles and Local Government Debt Management. Local Government Studies, 39(1), 1-26. http://doi.org/10.1080/03003930.2012.683861

Benito, B., Bastida, F., \& García, J. A. (2010). Explaining differences in efficiency: An application to Spanish municipalities. Applied Economics, 42(4), 515-528. http://doi.org/10.1080/00036840701675560

Benito, B., Bastida, F., \& Vicente, C. (2013). Creating Room For Manoeuvre: A Strategy To Generate Political Budget Cycles Under Fiscal Rules. Kyklos, 66(4), 467-496. http://doi.org/10.1111/kykl.12032

Cepiku, D., Mussari, R., \& Giordano, F. (2016). Local governments managing austerity: Approaches, determinants and impact. Public Administration, 94(1), 223-243. 
http://doi.org/10.1111/padm.12222

Davis, O. A, Dempster, M. A. H., \& Wildavsky, A. (1966). A Theory of the Budgetary Process. American Political Science Review, 60(3), 529-547.

Di Mascio, F., \& Natalini, A. (2015). Fiscal Retrenchment in Southern Europe: Changing patterns of public management in Greece, Italy, Portugal and Spain. Public Management Review, 17(1), 129-148. http://doi.org/10.1080/14719037.2013.790275

Hay, C. (1999). Crisis and the structural transformation of the state: Interrogating the process of change. British Journal of Politics \& International Relations, 1(3), 317-344. http://doi.org/10.1111/1467-856X.00018

Hay, C. (2013). Treating the Symptom Not the Condition: Crisis Definition, Deficit Reduction and the Search for a New British Growth Model. British Journal of Politics and International Relations, 15(1), 23-37. http://doi.org/10.1111/j.1467-856X.2012.00515.x

Heinelt, H., \& Hlepas, N.-K. (2006). Typologies of Local Government Systems. In H. Bäck, H. Heinelt, \& A. Magnier (Eds.), The European mayor: Political leaders in the changing context of local democracy (pp. 21-42). Wiesbaden: VS Verlag für Sozialwissenschaften.

John, P. (2001). Local governance in Western Europe. London: Sage.

Karyotis, G., Rüdig, W., \& Judge, D. (2014). Representation and Austerity Politics: Attitudes of Greek Voters and Elites Compared. South European Society and Politics, 19(February 2015), 435-456. http://doi.org/10.1080/13608746.2014.977478

Keller, B. (2014). The continuation of early austerity measures: The special case of Germany. Transfer: European Review of Labour and Research, 20(3), 387-402. http://doi.org/10.1177/1024258914538192

Ladner, A., \& Soguel, N. (2015). Managing the crises - how did local governments react to the financial crisis in 2008 and what explains the differences? The case of Swiss municipalities. Points for practitioners. International Review of Administrative Sciences, 81(4), 752-772. http://doi.org/10.1177/0020852314558033

Lowndes, V., \& McCaughie, K. (2013). Weathering the perfect storm? Austerity and institutional resilience in local government. Policy \& Politics, 41(4), 533-549. http://doi.org/10.1332/030557312X655747 
Natchez, P. B., \& Bupp, I. C. (1973). Policy and Priority in the Budgetary Process. The American Political Science Review, 67(3), 951-963.

Orr, K. (2009). Local government and structural crisis: An interpretive approach. Policy \& Politics, 37(1), 39-55. http://doi.org/10.1332/147084408X349747

Overmans, J. F. A., \& Noordegraaf, M. (2014). Managing austerity: Rhetorical and real responses to fiscal stress in local government. Public Money \& Management, 34(2), 99106. http://doi.org/10.1080/09540962.2014.887517

Overmans, J. F. A., \& Timm-Arnold, K.-P. (2015). Managing Austerity: Comparing municipal austerity plans in the Netherlands and North Rhine-Westphalia. Public Management Review, 2-20. http://doi.org/10.1080/14719037.2015.1051577

Page, E., \& Goldsmith, M. (1987). Central and local government relations: A comparative analysis of West European unitary states. London: Sage.

Peters, B. G. (2010). Paying for government: the budgetary process. In The Politics of Bureaucracy (pp. 261-293). London and New York: Routledge.

Pollitt, C. (2010). Cuts and Reforms - Public services as we move into a new era. Society and Economy, 32(1), 17-31. http://doi.org/10.1556/SocEc.32.2010.1.3

Raudla, R., Savi, R., \& Randma-Liiv, T. (2013). Literature Review on Cutback Management. Cocops, (March), 52.

Shaw, K. (2012). The Rise of the Resilient Local Authority? Local Government Studies, 38(3), 281-300. http://doi.org/10.1080/03003930.2011.642869

Wolman, H., \& Goldsmith, M. (1992). The study of urban politics and policy. In H. Wolman \& M. Goldsmith (Eds.), Urban politics and policy: A comparative approach (pp. 256-257). Oxford: Basil Blackwell. 
Table 1. Classification, \% of implementation and impact weight of austerity measures in catalan municipalities 2013

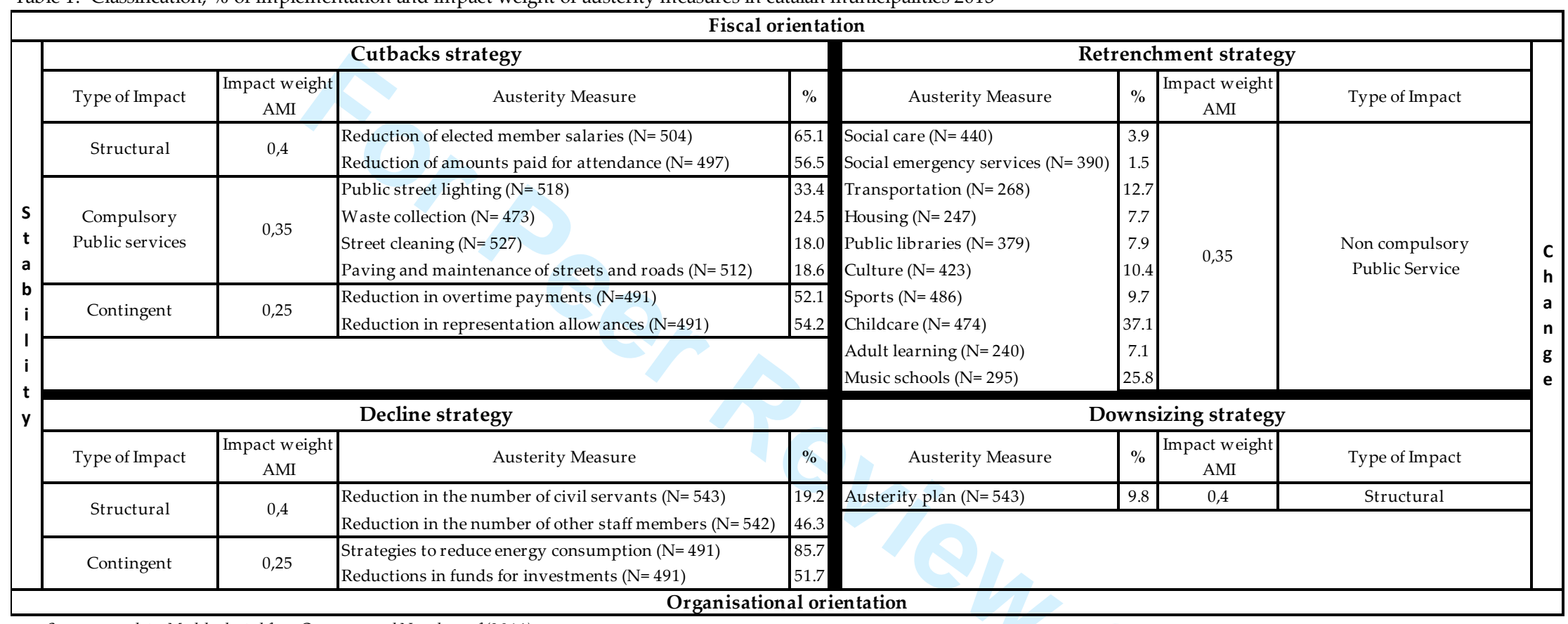

Source: own data. Model adapted from Overmans and Noordeg raaf (2014) 
TABLE 2 Austerity Measures Index (AMI)

\begin{tabular}{|c|c|c|}
\hline \multicolumn{2}{|l|}{$\mathbf{N}$} & 393 \\
\hline \multicolumn{2}{|l|}{ Mean } & 0.3770850608 \\
\hline \multicolumn{2}{|l|}{ Median } & 0.3650000000 \\
\hline \multicolumn{2}{|l|}{ Mode } & 0.20500000 \\
\hline \multicolumn{2}{|c|}{ Standard deviation } & 0.16753842756 \\
\hline \multicolumn{2}{|l|}{ Variance } & 0.028 \\
\hline \multicolumn{2}{|c|}{ Minimum } & 0.06250000 \\
\hline \multicolumn{2}{|c|}{ Maximum } & 0.80750000 \\
\hline & Q1 & 0.2475000000 \\
\hline \multirow[t]{2}{*}{ Quartiles } & Q2 & 0.3650000000 \\
\hline & Q3 & 0.4930681818 \\
\hline
\end{tabular}

TABLE 3 Budget spending per habitant

\begin{tabular}{|ll|c|c|c|}
\hline & & Spending/hab 2009 & Spending/hab 2013 & Difference in spending 09-13/hab \\
\hline N & Total & 553 & 612 & 547 \\
& Missing & 72 & 13 & 78 \\
Mean & & 1534.56 & 1067.71 & -459.01 \\
Median & & 1374.11 & 962.47 & -375.04 \\
Standard deviation & 672.381 & 445.483 & 533.328 \\
Variance & & 452.096 .631 & 198.455 .189 & $284_{2} 439.136$ \\
Minimum & & 674 & 519 & -7441 \\
Maximum & & 8,988 & 6,704 & 1,31 \\
& Q1 & 1164.17 & 825.37 & -586.00 \\
Quartiles & Q2 & 1374.11 & 962.47 & -375.04 \\
& Q3 & 1708.47 & 1174.63 & -223.01 \\
\hline
\end{tabular}

Source: own data 
Table 4

Hypothesis 1

\begin{tabular}{lll}
\hline & Model 1 & Model 2 \\
\hline Per capita debt 2013 & 0.041 & 0.043 \\
& $(0.007)^{*}$ & $(0.006)^{*}$ \\
Unemployment 2013 (\%) & -0.001 & -0.003 \\
& $(0.752)$ & $(0.489)$ \\
Density 2013 & 0.000 & 0.00 \\
& $(0.950)$ & $(0.747)$ \\
Logged population 2013 & 0.119 & 0.122 \\
Ideology of mayor [Ref. Left] & $(0.000)^{*}$ & $(0.000)^{*}$ \\
& & 0.034 \\
Strength of local government & & $(0.056)$ \\
& & 0.000 \\
Coalition government [Ref. Yes] & & $(0.561)$ \\
& & -0.019 \\
Constant & -0.173 & $(0.305)$ \\
& $(0.023)^{*}$ & $(0.255)$ \\
\hline Adjusted R-Square & 0.191 & 0.196 \\
N & 321 & 321 \\
\hline
\end{tabular}

* $\mathrm{p}<0.05$

Dependent variable: AMI

\begin{tabular}{lll} 
Table 5 & \multicolumn{2}{l}{ Hypothesis 2 } \\
\hline Revenue tax (mean 2009) & -0.002 & -0.001 \\
& $(0.830)$ & $(0.927)$ \\
\% of population change 13-09 & 1.294 & 1.420 \\
Difference in per capita debt (13-09) & $(0.850)$ & $(0.833)$ \\
& 40.357 & 60.43 \\
\% of change in unemployment (13-09) & $(0.638)$ & $(0.479)$ \\
& 2.353 & 1.987 \\
Ideology of mayor [Ref. Left] & $(0.096)$ & $(0.157)$ \\
& & -84.976 \\
Strength of local government & & $(0.161)$ \\
& & -6.939 \\
Coalition government [Ref. Yes] & & $(0.003)^{*}$ \\
& & -1.218 \\
Index of Municipal Austerity (AMI) & & $(0.984)$ \\
& & -342.78 \\
Constant & & $(0.056)$ \\
& & 107.404 \\
\hline Adjusted R-Square & -491.212 & \\
N & $(0.002)^{*}$ & $(0.638)$ \\
\hline P $<0.05$ & -0.12 & 0.033 \\
Dependent variable: per capita budget change 2013-2009 & & 237 \\
\hline
\end{tabular}


Figure 1 Scatter plot of AMI \& 2013 population (logged)

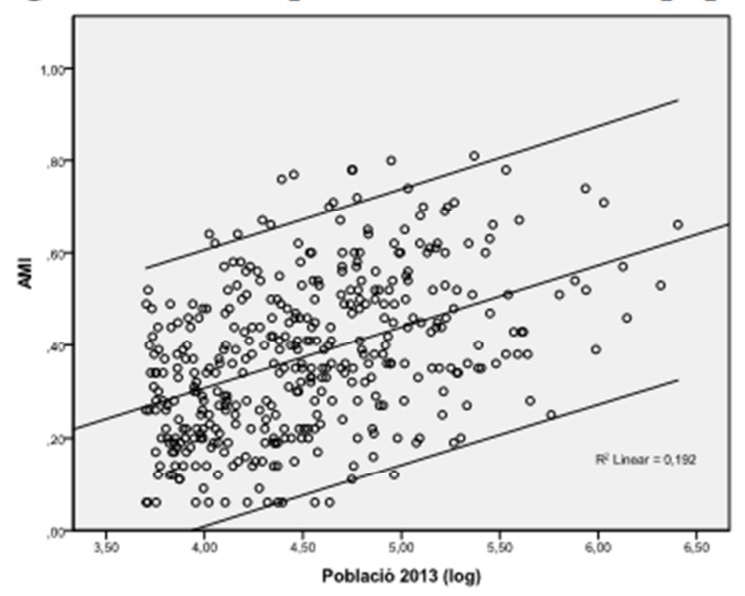

Figure 2 Scatter plot of difference 2009-2013 in public spending per habitant \& AMI

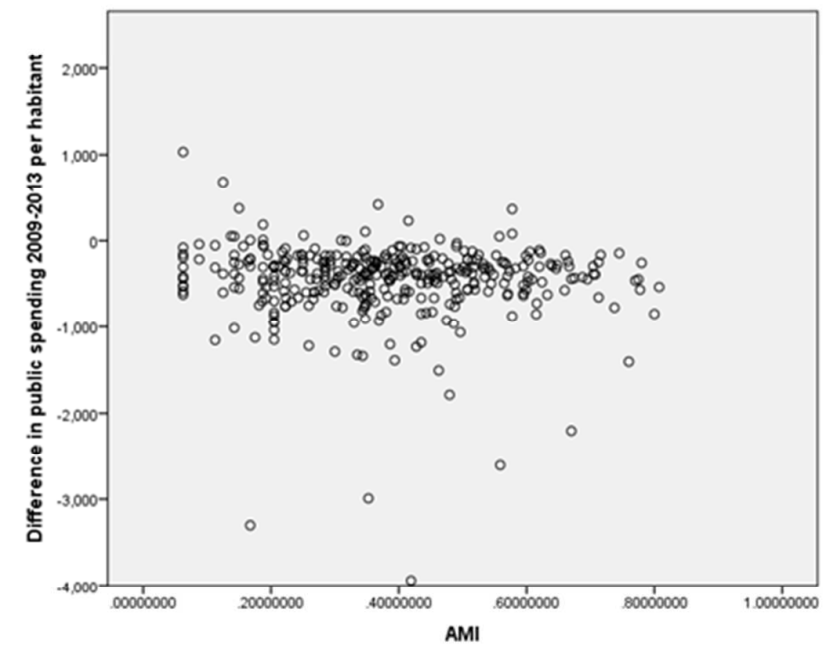

Source: own data 


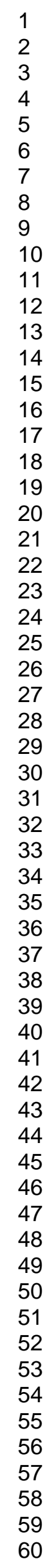

